\title{
The Influence of Shell Permeability on Stability of Upstream Slope during Rapid Drawdown - Khassa Chai Earth Dam as a Case Study
}

\author{
Krikar M Gharrib Noori \\ MLT Department \\ Koya Technical Institute \\ Erbil Polytechnic University \\ Erbil, Kurdistan-Iraq
}

\author{
Sirwan G Salim ${ }^{2}$ \\ City Planning Engineering Department \\ Technical College of Engineering \\ Sulaimani Polytechnic University \\ Sulaimani, Kurdistan- Iraq
}

(Received 20/6/2021 , Accepted 6/10/2021)

\begin{abstract}
Several factors affect the stability of earth dam during sudden drawdowns such as permeability and mechanical properties of soil, upstream side slope, drawdown ratio, and drawdown rate. This paper investigates the influence of shell permeability on earth dam upstream slope stability and its role in the change of pore water pressure at different locations of the embankment during the sudden drawdown, using different limit equilibrium methods. To accomplish the objective of this study, (Geo Studio 2012 Software) as one of the powerful geotechnical programs was used for the modeling and numerical analysis. The study shows that decreasing in the shell permeability resulted in the reduction of pore water pressure dissipation and variation of shell hydraulic conductivity plays a vital role in the overall stability of the upstream slope under rapid drawdown conditions.
\end{abstract}

Keywords: Slope Stability, Rapid Drawdown, Permeability, Safety Factor, Geo Studio 2012.

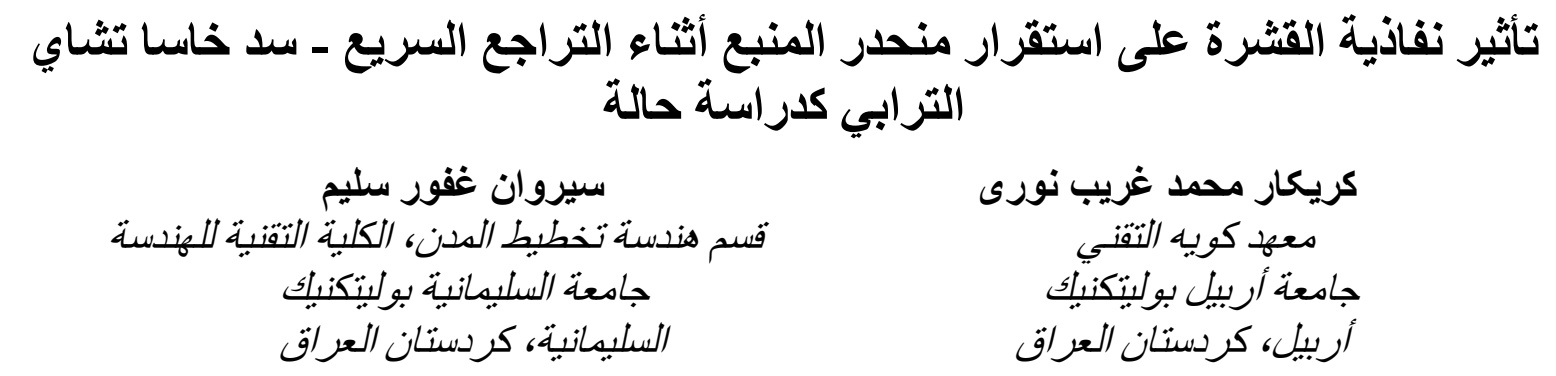

الملخص

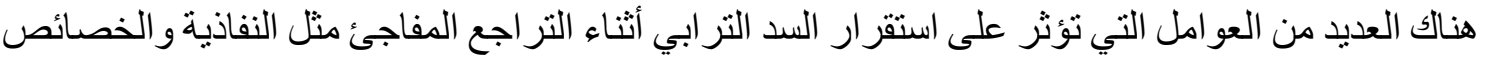

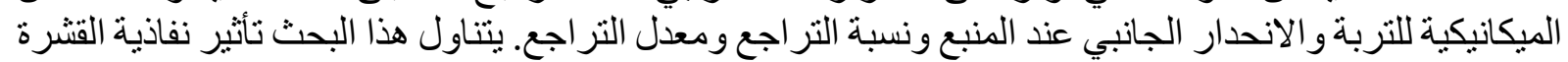

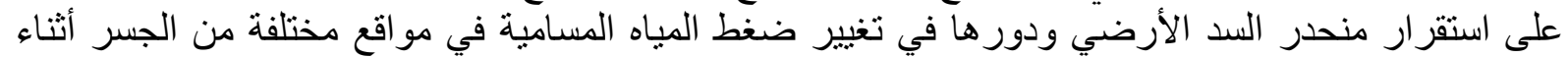

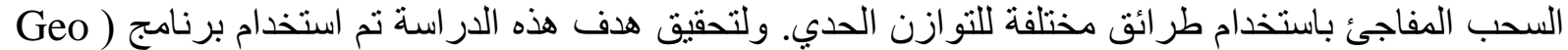
Studio 2012 Software

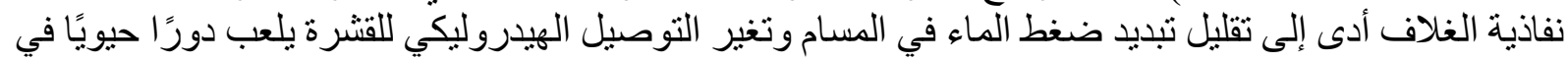

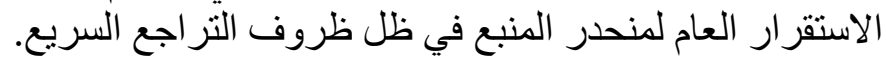

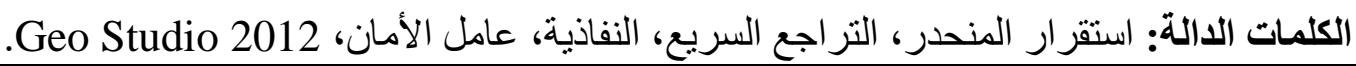




\section{INTRODUCTION}

Slope stability analysis of an earth dam is always focused on in the construction stages and design to ensure safe operation during its life. Steady-state condition is critical for downstream slope. On the other hand, sudden drawdown is the worst case for upstream slope. The upstream slope may be destabilized as a result of the fast reduction of water level in the reservoir and slow dissipation of water. Some earth dam failures due to sudden drawdown such as (Pilarcitos Dam, south of San Francisco), and (Walter Boudin Dam in Alabama) have been listed in (Duncan, et al., 1990), and (Berilgen, 2007).

Beiranvand, et al., (2019) examined the effect of internal friction angle and side slope ratio on the stability of a heterogeneous dam, based on the results, the researchers concluded that the angle of internal friction and side slope ratio has a considerable effect on the stability of the dam. Berilgen, (2017) emphasized that the stability of the submerged slopes during sudden drawdown depends on how fast the water dissipates. Mishal and Khayyum (2018) derived an empirical equation to find earth dam safety factors for similar geometries and soil properties without slope stability analysis, they assumed different soil parameters to derive the formula and then compared the results of the formula with the results of GeoStudio, there was a good agreement between the results and the standard error was 0.0714 .

Moharrami, et al., (2013) studied rapid drawdown condition under the effect of horizontal drains on the stability of the upstream slope, the results revealed that the horizontal drains in the upstream shell of the dam has a positive impact on the stability of the dam and is cost-effective. Malekpour, et al., (2012) mentioned that using the horizontal drain with proper lengths and thickness guarantees the safety of the dam during transient seepage as a result of the fast lowering of reservoir water level. Salim, (2013) examined the influence of upstream and downstream gradient on the stability of zoned earth-fill dam during the rapid drawdown, based on the study, upstream slope has a great role on the stability of the dam during this case, and by contrast, the effect of the downstream slope is very small and can be neglected.

The selection of suitable materials for earth dam construction has a marked effect on the stability of the dam, therefore, the parametric study of the material properties is very important and shell permeability is one of the important parameters. In this study, a computer software GeoStudio 2012 is utilized to examine the effect of shell hydraulic conductivity on factors of safety and pore water pressure inside the embankment under rapid drawdown conditions. Khassa Chai Dam in Kirkuk-Iraq has been modeled as a case study.

\section{CASE STUDY - KHASSA CHAI EARTH DAM}

The Khassa Chai Dam is located upstream of Kirkuk on the Khassa Chai River. The Khassa Chai River flows into the Al-Adhaim Dam reservoir as a tributary of the Zaghitun River. The dam lies near the Kuchuk hamlet, which is roughly 10 kilometers northeast of Kirkuk, as seen in Figure 1.

Khassa Chai is an earth-fill dam with a central (silty-clay) core, this dam was constructed on a foundation of different formations that consists of stiff silty-clay, coarse 
grain gravel, and organic matter. It is situated near Kuchuk village, on the Khassa River upstream of Kirkuk city in Iraq (coordinates at $39^{\circ} 33^{\prime} 780^{\prime \prime} \mathrm{N}, 45^{\circ} 22^{\prime} 41^{\prime \prime} \mathrm{E}$ ). The dam height is about $58 \mathrm{~m}$, its crest width is $14 \mathrm{~m}$, and the base width is $315 \mathrm{~m}$, while the crest total length is about $2215 \mathrm{~m}$. A chimney filter discharge was adopted along the downstream side of the core and flattened with a horizon at the downstream side of the dam, with a thickness of $(2 \mathrm{~m})$. Figure (2) shows a typical cross-section of Khassa Chai Dam, and the materials properties of components of the dam are shown in Table (1), (Zedan, et al., 2017), and (Khassaf and Madhloom, 2019), (Alfatlawi, et al., 2020).

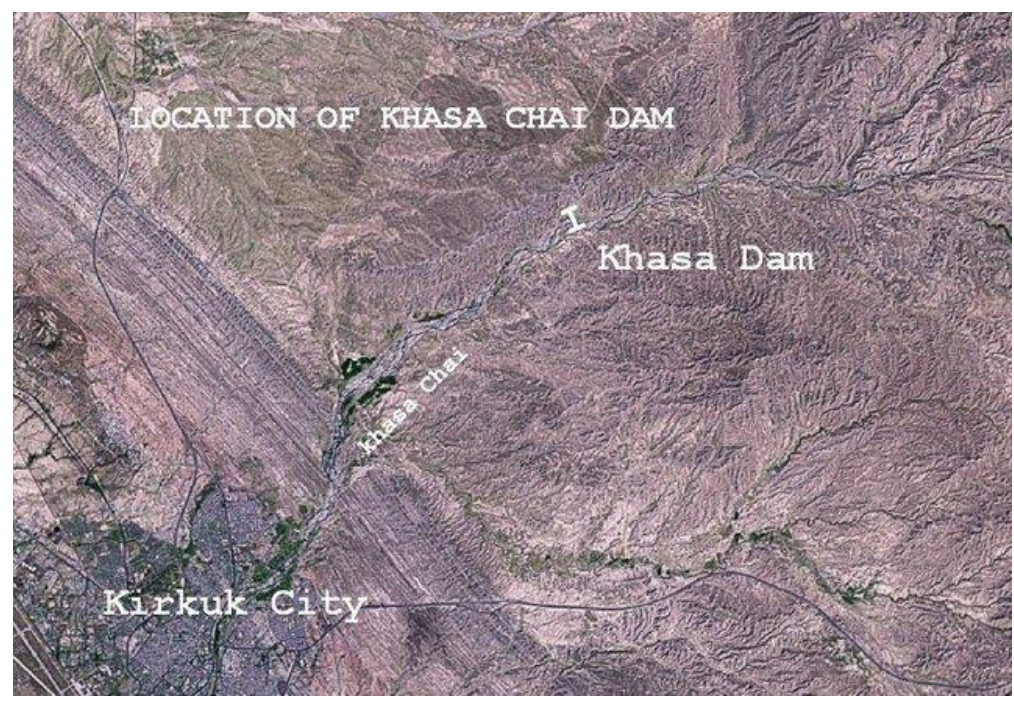

Fig. 1: Location of Khassa Chai dam (Center of Engineering Designs and Studies).

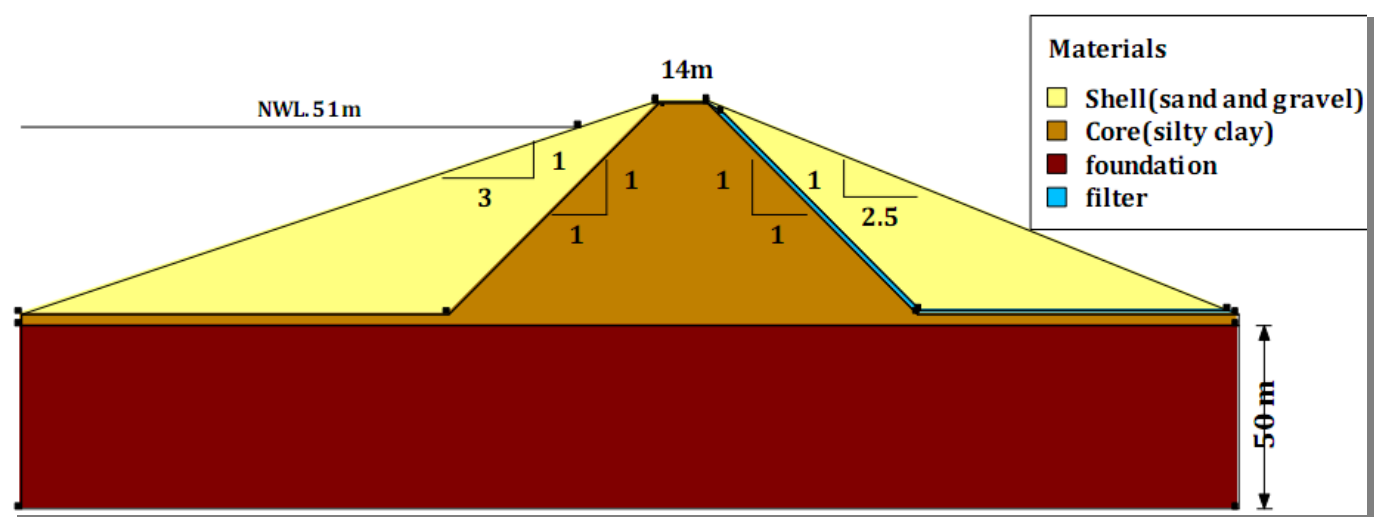

Fig. 2: Typical cross-section of Khassa Chai Dam (Alfatlawi, et al., 2020).

Table 1: Material properties of Khassa Chai Earth Dam (Zedan, et al., 2017), and (Khassaf and Madhloom, 2019), (Alfatlawi, et al., 2020).

\begin{tabular}{|c|c|c|c|c|c|}
\hline Materials & $\begin{array}{c}\text { Unit weight } \\
\left(\mathbf{K N} / \mathbf{m}^{\mathbf{3}}\right)\end{array}$ & $\begin{array}{c}\text { Permeability K } \\
(\mathbf{m} / \mathbf{s})\end{array}$ & $\begin{array}{c}\text { Water } \\
\text { Content } \%\end{array}$ & $\begin{array}{c}\text { Cohesion } \\
(\mathbf{K p a})\end{array}$ & $\begin{array}{c}\text { Friction } \\
\text { angle } \\
(\mathbf{d e g r e e s})\end{array}$ \\
\hline Core & 17.52 & $2.25 \times 10^{-10}$ & 25 & 85 & 9.28 \\
\hline Shell & 21.9 & $1.25 \times 10^{-5}$ & 15 & 0 & 38 \\
\hline Filter & 18 & $1.25 \times 10^{-5}$ & 15 & 0 & 35 \\
\hline Drain & 23 & $1 \times 10^{-2}$ & 10 & 0 & 35 \\
\hline Foundation & 21.8 & $1 \times 10^{-10}$ & 30 & 173 & 21.76 \\
\hline
\end{tabular}




\section{METHODOLOGY}

To examine the stability of dam upstream slope during drawdown under the effect of different shell permeability and analysis of transient seepage conditions to determine the pore water pressure, the dam was simulated. Having the geometrical and geotechnical properties of the dam, and using the numerical program of SEEP/W and SLOPE/W in Geostudio 2012 software, two-dimensional modeling of Khassa Chai earth dam is performed.

The case is investigated to see how different shell permeability values $\left(\mathrm{K}=1.25^{*} 10-4 \mathrm{~m} / \mathrm{s}, 1.25^{*} 10-5 \mathrm{~m} / \mathrm{s}, 1.25^{*} 10-6 \mathrm{~m} / \mathrm{s}, 1.25 * 10-7 \mathrm{~m} / \mathrm{s}\right)$ affect the stability of the upstream slope for a drawdown rate of $2 \mathrm{~m} / \mathrm{day}$, as well as computing the factor of safety and pore water pressure on the dam upstream slope using several limit equilibrium methods like Morgenstern-Price, Bishop, Janbu, and ordinary method.

From the typical reservoir level of $51 \mathrm{~m}$, the maximum water level to drawdown is almost 51m (Alfatlawi, et al., 2020). SEEP/W solves the governing equations of flow via earth dams using a finite element mesh for a two-dimensional flow model in saturated and unsaturated soils. The dam was simulated by sketching a cross-section of the Khassa Chai case study, which was then used in a grid of finite elements with 3 nodes and 4 nodes of triangular and quadrilateral elements, respectively, as shown in Figure (3).

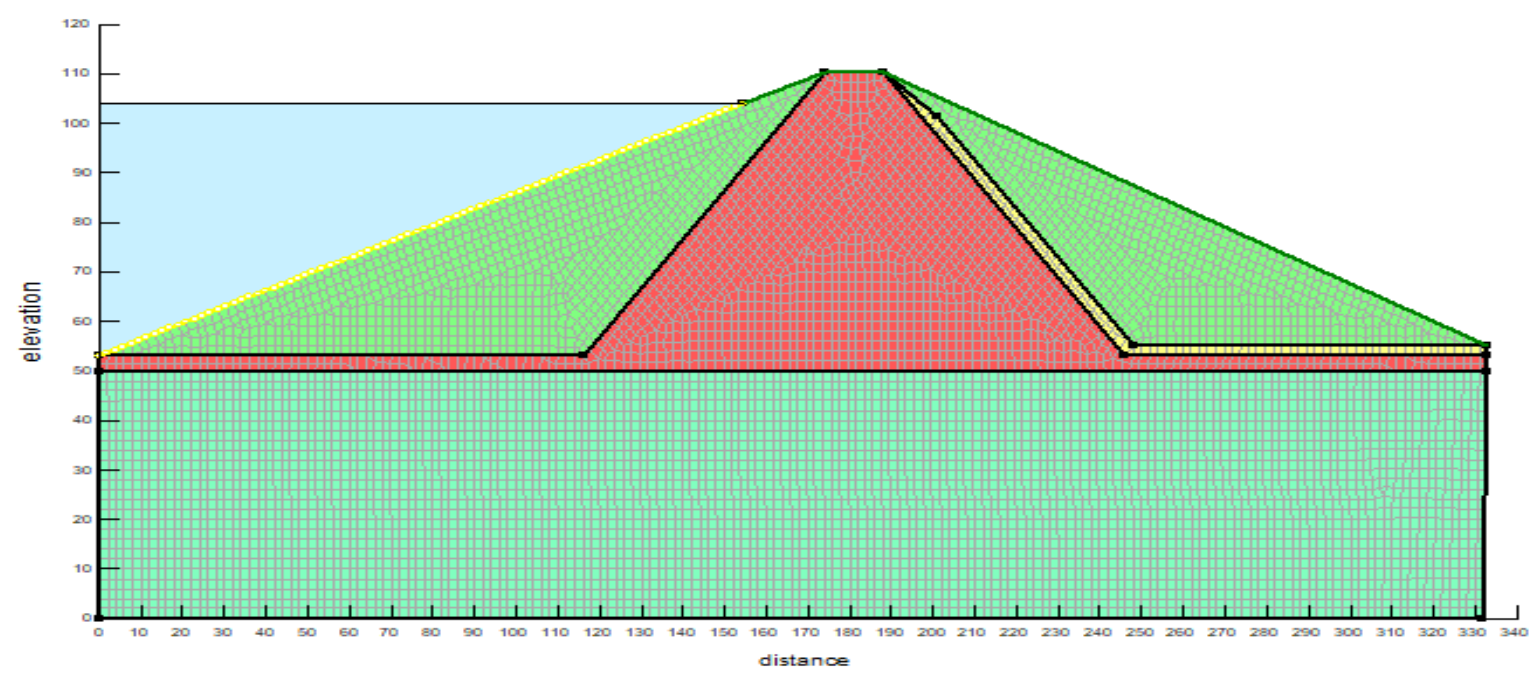

Fig. 3: Mesh generation of Khassa Chai earth dam.

Constant total head limits with a value of $51 \mathrm{~m}$ were defined as the water level at the reservoir $7 \mathrm{~m}$ below the dam's crest. The initial pore-water pressure distribution in SLOPE/W was defined using steady-state seepage results as a parent in the study of transient seepage situations. To establish trial failure surfaces for each modeling instance, the entrance and exit slip surface approach is applied in this work. For each drawdown scenario, the package analyzes all trial surfaces to identify a minimal factor of safety that is a key surface under the influence of varied shell permeability. 


\section{THEORY OF ANALYSIS}

\section{ANALYSIS OF SEEPAGE}

The rule of Darcy governs water flow in both unsaturated and saturated soil, and SEEP/W is based on this formula (Noori, et al., 2018) and (SEEP/W, 2012).

$$
q=\boldsymbol{k} \cdot \boldsymbol{i}
$$

Where $q$ denotes flow rate, $k$ represents hydraulic conductivity, and $i$ mean hydraulic gradient.

Modeling two-dimensional seepage in steady-state and transient conditions in the dam before and during drawdown is done using finite element water flow equations to governing differential equations implemented in SEEP/W (SEEP/W, 2012). (Rulon, J.J., and Freeze, R.A., 1985). For two-dimensional seepage, the typical governing differential equation is:

$$
\frac{\partial}{\partial x}\left(k_{x} \frac{\partial H}{\partial x}\right)+\frac{\partial}{\partial y}\left(k_{y} \frac{\partial H}{\partial y}\right)+Q=\frac{\partial \theta}{\partial t}
$$

Where $\mathrm{H}$ indicates total head, $\mathrm{kx}$ represents hydraulic conductivity in the $\mathrm{x}$ direction, ky denotes hydraulic conductivity in the y-direction, $\mathrm{Q}$ indicates applied boundary flux, vw Means volumetric water content, and t represents time.

\section{THEORY OF SLOPE STABILITY ANALYSIS}

Limit equilibrium analysis methods have been used to compute embankment slope stability for many years to solve geotechnical engineering challenges. SLOPE/W calculates the factor of safety against failure using the theory of limit equilibrium for moments and forces. The factor of safety (FoS) is defined as the amount by which the soil shear strength should be reduced to put the soil mass into a limited equilibrium condition alongside a chosen slip surface (SLOPE/W, 2012).

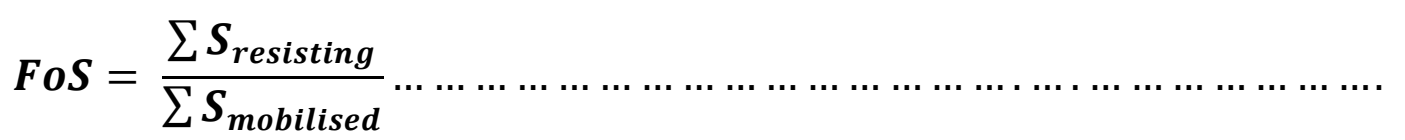

Different limit equilibrium methods have been used in this study to analyze the slope of the embankment dam during drawdown conditions, such as Bishop (Bishop, 1955) (Bishop, A. W., and Morgenstern, N., 1960), Morgenstern-Price (Morgenstrern, N.R., and Price, V.E., 1965), Janbu (Janbu, 1954) (Janbu, 1968), and Swedish Ordinary or Fellenius method (Fellenius, 1936). Figure (4) depicts all of the forces operating on a circular slope. 


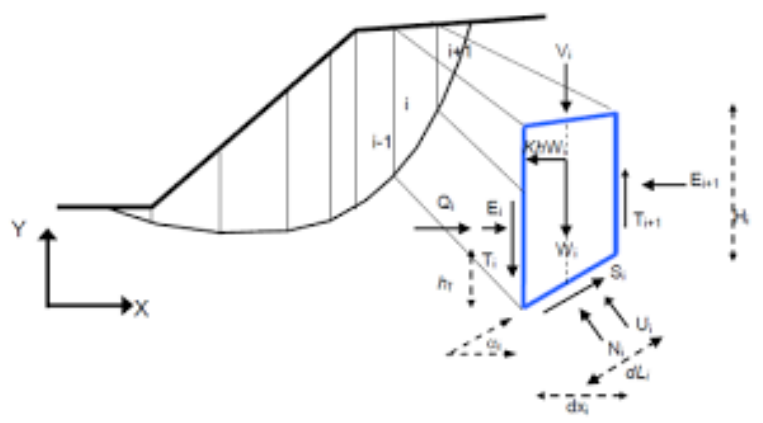

Fig. 4: Forces acting on a slice through a sliding mass with a circular slip surface (SLOPE/W, 2012).

\section{Swedish Ordinary or Fellenius Method:}

This is the first developed method of slices presented in the literature. It considers moment equilibrium, which means inter-slice normal and shear forces are ignored. The method is simple in solving the (FoS), due to not considering the iteration process in the equation (Alfatlawi, et al., 2020) (SLOPE/W, 2012). Therefore, the (FoS) is expressed as:

$$
\boldsymbol{F o S}_{m}=\frac{\sum\left(c^{\prime} \boldsymbol{\beta}+(W \cos \alpha-\mathbf{u} \beta) \tan \emptyset^{\prime}\right)}{\sum W \sin \alpha}
$$

Where $c^{\prime}=$ cohesion, $\phi^{\prime}=$ internal friction angle, $\boldsymbol{\beta}=$ slice base length, $(\mathrm{m})$, $\mathrm{W}=$ weight of each slice $(\mathrm{kN}), \mathrm{u}=$ pore water pressure $\left(\mathrm{kN} / \mathrm{m}^{2}\right), \alpha=$ inclination of slip surface at the middle of slice.

\section{Bishop Method:}

Bishop promoted this approach in the 1950s by including inter-slice normal forces while ignoring inter-slice shear forces. Because the FoS is present on both sides of the equation, the trial value for the factor of safety is assumed, and the amount, $\mathrm{m}$, is calculated from the equation (SLOPE/W, 2012).

$$
\begin{aligned}
& F o S=\frac{1}{\sum W \sin \alpha} \sum\left[\frac{c^{\prime} \beta+W \tan \phi-\frac{c \beta}{F o S} \sin \alpha \tan \alpha}{m_{\alpha}}\right] \\
& m_{\alpha}=\operatorname{CoS}_{\alpha} \frac{\operatorname{Sin}_{\alpha} \tan \emptyset^{\prime}}{\mathrm{FoS}}
\end{aligned}
$$

\section{Morgenstern-Price Method:}

In (1965) Morgenstern and Price proposed a method considering normal and shear inter-slice forces together, and moment equilibrium, which permits for a variety of userselected inter-slice force functions such as - Constant - Half-sine - Clipped-sine • Trapezoidal • Data-point specified (Alfatlawi, et al., 2020) (SLOPE/W, 2012). 


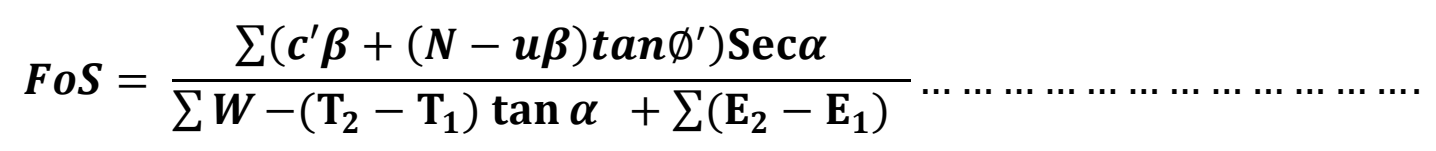

Where $\mathrm{u}=$ pressure of pore water; $\mathrm{W}=$ slic's weight; $\alpha=$ bottom slice inclination; $\mathrm{E}=$ inter slice normal force $(\mathrm{kN}) ; N=$ effective normal force on the slice base $(\mathrm{kN}) ; \mathrm{S}=$ the shear force on the slice base $(\mathrm{kN})$; and $\mathrm{T}=$ the vertical interslice shear force $(\mathrm{kN})$.

\section{Janbu Method:}

This method satisfies only overall horizontal force equilibrium, but not overall moment equilibrium (Abbas, et al., 2017), and (SLOPE/W, 2012).

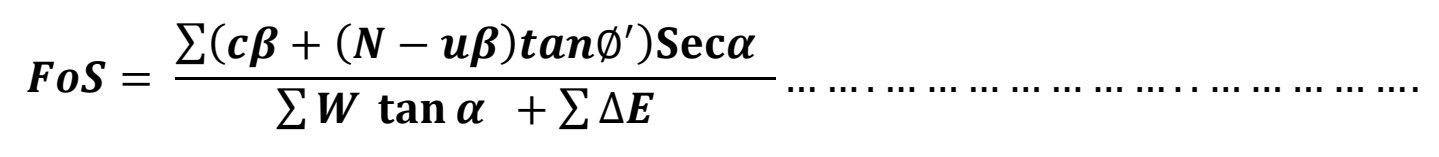

$\sum \Delta \boldsymbol{E}=\boldsymbol{E} \mathbf{2}-\boldsymbol{E} \mathbf{1}=$ net interslice normal forces (zero if there is no horizontal force).

\section{RESULTS AND DISCUSSION}

This study deals with the effect of shell permeability on the stability of the upstream slope during sudden drawdown (drawdown rate, DDR $2 \mathrm{~m} /$ day). Numerical analysis is implemented for some values of shell permeability such as $\left(\mathrm{K}=1.25^{*} 10-4\right.$ $\left.\mathrm{m} / \mathrm{s}, 1.25^{*} 10-5 \mathrm{~m} / \mathrm{s}, 1.25^{*} 10-6 \mathrm{~m} / \mathrm{s}, 1.25^{*} 10-7 \mathrm{~m} / \mathrm{s}\right)$, the other parameters are kept constant. The results of the analysis using (Morgenstern-Price, Bishop, Janbu, and Ordinary method), are shown in Figures (5).

Regarding the stability of the dam, there is a considerable change in the factor of safety concerning the change of shell permeability. According to the outcomes, the low permeability of the shell gave a lower factor of safety of the upstream slope. For instance, the factor of safety using (Morgenstern-Price method) for the shell permeability $\left(1.25^{*} 10-4 \mathrm{~m} / \mathrm{s}\right)$ is $(1.15)$, while for shell permeability $\left(1.25^{*} 10-7 \mathrm{~m} / \mathrm{s}\right)$ is $(0.25)$, the value of safety factor decreased substantially to almost twenty percent of its value. This is because that the stability of upstream slope during drawdown is mainly based on how quickly the pore water pressure dissipates, and the dissipation of water depends on two major principles which are a time to squeeze of water from the upstream face, and the permeability of the soil porous media in which water remained in, after draw-downing the reservoir level (SEEP/W, 2012). 

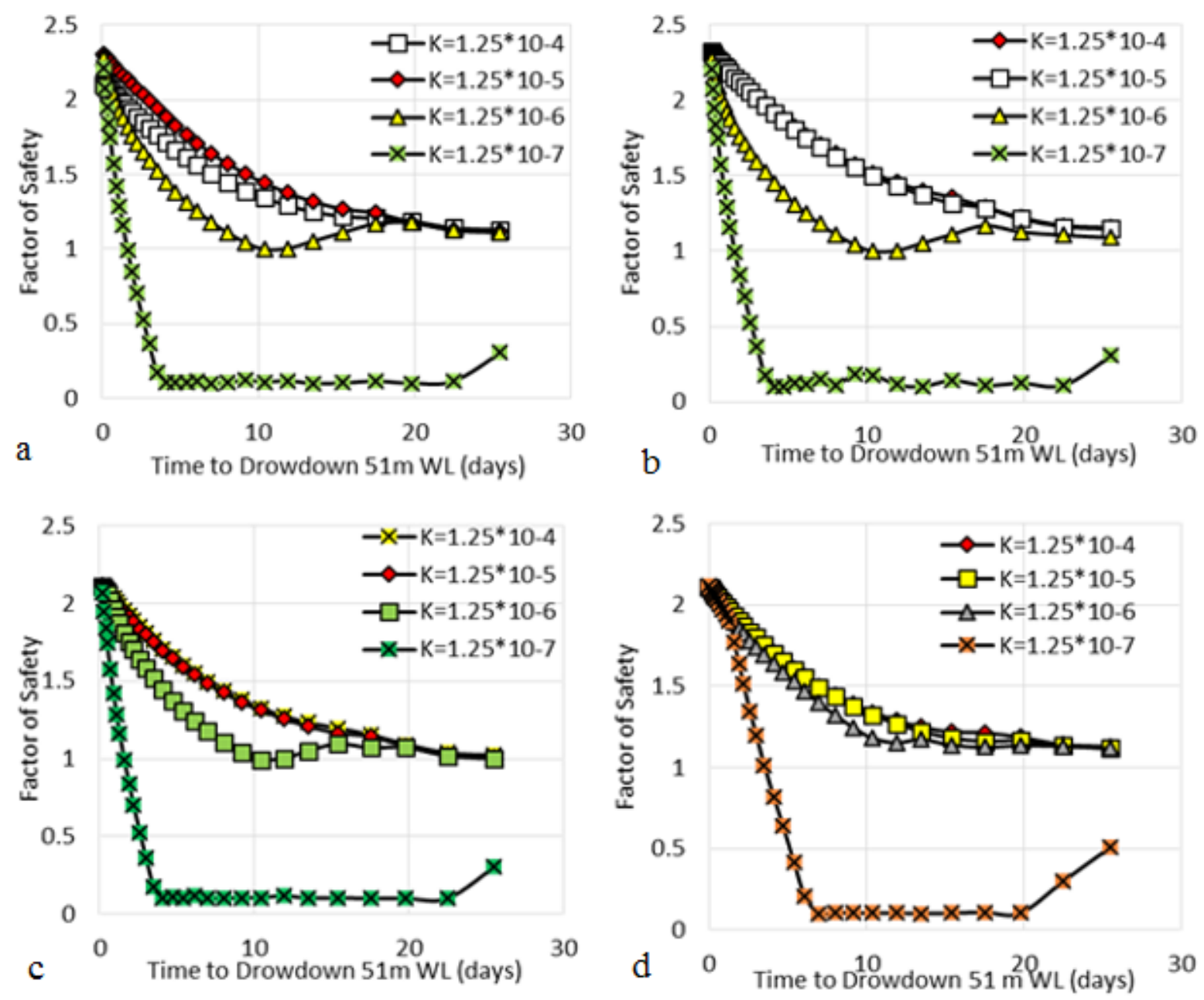

Fig. 5: Variation of the factor of safety with various shell permeability using (a) MorgensternPrice, (b) Bishop, (c) Janbu, and (d) Ordinary Method.

From the figures, the results of $\left(K=1.25^{*} 10-4 \mathrm{~m} / \mathrm{s}\right.$ and $\left.\mathrm{K}=1.25^{*} 10-5 \mathrm{~m} / \mathrm{s}\right)$ are quite similar, and a slight difference in the factor of safety can be noticed for $\left(\mathrm{K}=1.25^{*} 10-6\right.$ $\mathrm{m} / \mathrm{s})$, while for $\left(\mathrm{K}=1.25^{*} 10-7 \mathrm{~m} / \mathrm{s}\right)$ the safety factor declined speedily during the early days of the drawdown and the dam would be unstable for the rest of the period. In addition, the minimum factor of safety for $(\mathrm{K}=1.25 * 10-4 \mathrm{~m} / \mathrm{s}$ and $\mathrm{K}=1.25 * 10-5 \mathrm{~m} / \mathrm{s})$ is at the end of the time, whereas for $\left(\mathrm{K}=1.25 * 10-6 \mathrm{~m} / \mathrm{s}\right.$ and $\left.\mathrm{K}=1.25^{*} 10-6 \mathrm{~m} / \mathrm{s}\right)$, it reached minimum value before the end of the duration and then slightly increased at the last time of the period. This is due to higher permeability allows for the dissipation of pore water pressure, resulting in increased shear resistance of the material and eventually improving the stability of the dam upstream slope. The minimum safety factor for all cases can be summarized and presented in Table (2).

In Figure (6), the results of factors of safety concerning different methods for variant shell permeability are shown. Generally, the factor of safety for the Morgenstern-Price method has a greater value compared to the other methods, whereas the minimum value was obtained from the Janbu method. Moreover, the initial safety factor of Morgenstern-Price and Bishop is nearly the same around (2.3), and it is roughly (2.1) for Janbu and Ordinary method. 
Table 2: Variant minimum factor of safety with respect to change of shell permeability for different methods.

\begin{tabular}{|l|l|l|l|l|}
\hline Methods & $\begin{array}{l}\text { K m/s } \\
\mathbf{1 . 2 5} * \mathbf{1 0}^{-4}\end{array}$ & $\begin{array}{l}\text { K m/s } \\
\mathbf{1 . 2 5} * \mathbf{1 0}^{-\mathbf{5}}\end{array}$ & $\begin{array}{l}\mathbf{K ~ m} / \mathbf{s} \\
\mathbf{1 . 2 5} * \mathbf{1 0}^{-\mathbf{6}}\end{array}$ & $\begin{array}{l}\mathbf{K ~ m} / \mathbf{s} \\
\mathbf{1 . 2 5} * \mathbf{1 0}^{-\mathbf{7}}\end{array}$ \\
\hline Morgenstern-Price & 1.156 & 1.146 & 0.997 & 0.25 \\
\hline Bishop & 1.128 & 1.113 & 0.997 & 0.18 \\
\hline Janbu & 1.022 & 1.008 & 0.996 & 0.1 \\
\hline Ordinary & 1.128 & 1.120 & 1.116 & 0.18 \\
\hline
\end{tabular}

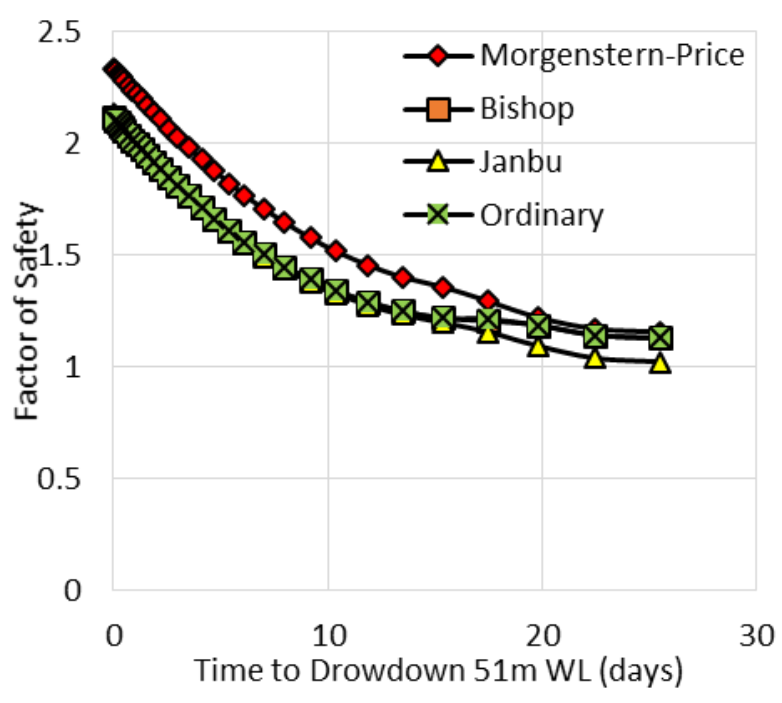

(a)

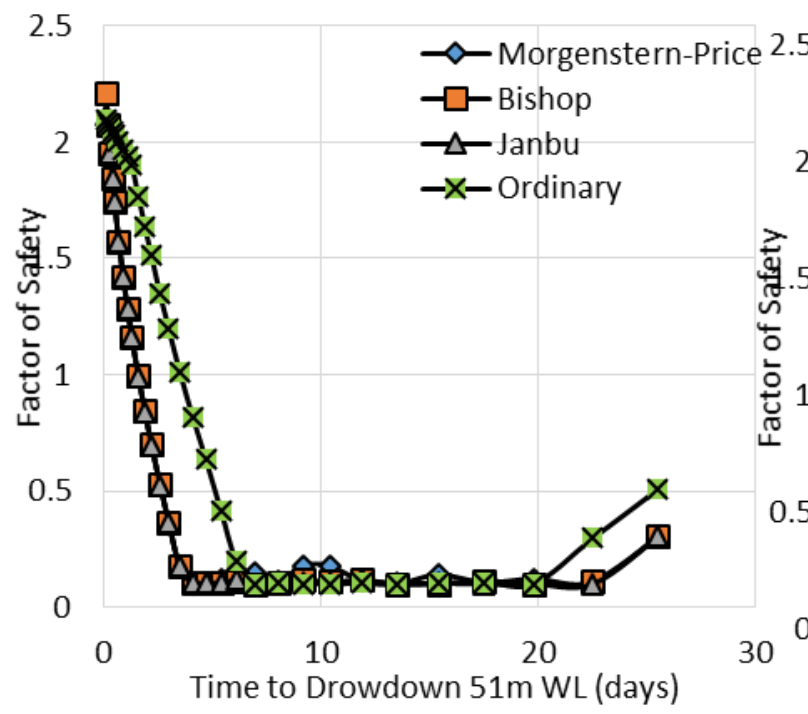

(c)

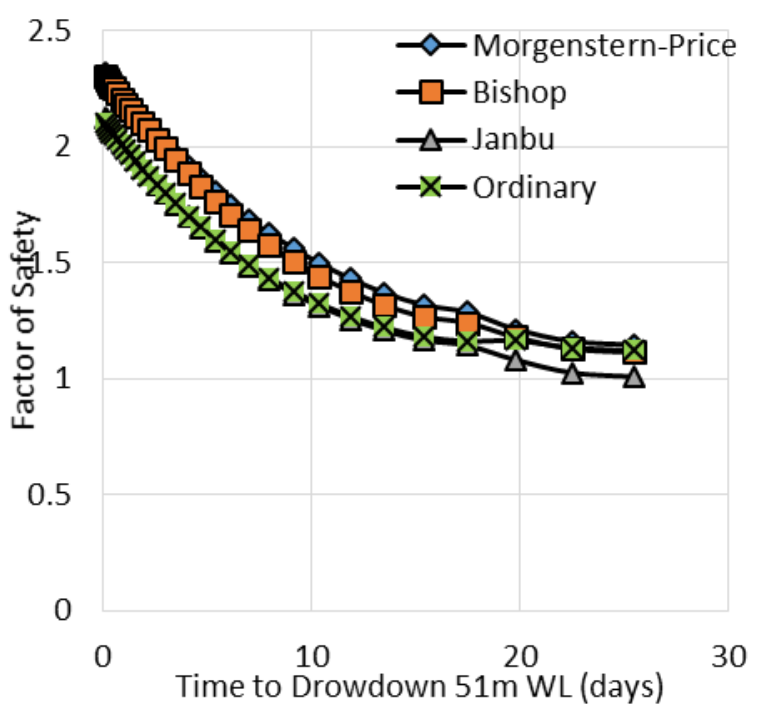

(b)

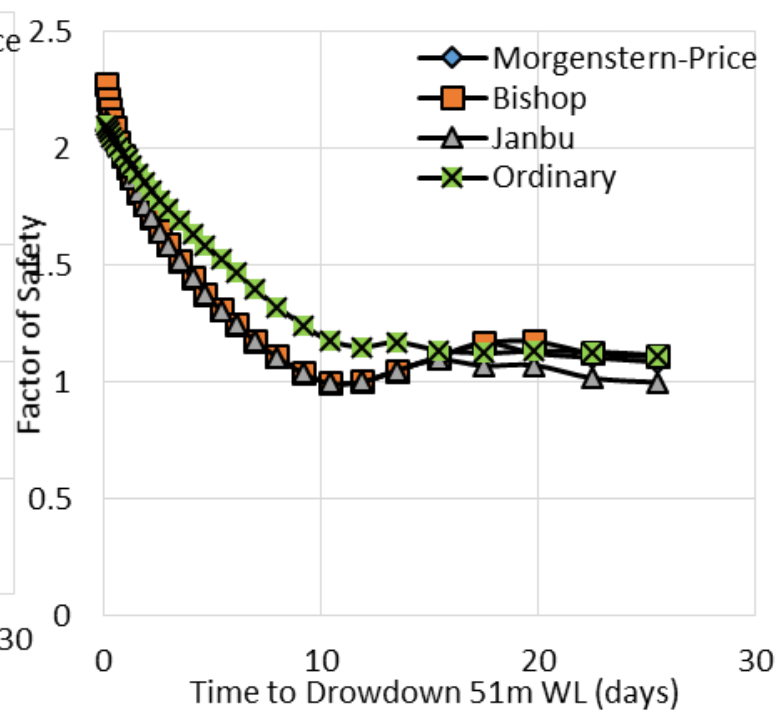

(d)

Fig. 6: Comparison of factor of safety with respect to different methods for (a) $\mathrm{K}=1.25^{*} 10^{-4}$ $\mathrm{m} / \mathrm{s}$ (b) $\mathrm{K}=1.25^{*} 10^{-5} \mathrm{~m} / \mathrm{s}$ (c) $\mathrm{K}=1.25^{*} 10^{-6} \mathrm{~m} / \mathrm{s}$, and (d) $\mathrm{K}=1.25^{*} 10^{-7} \mathrm{~m} / \mathrm{s}$.

To explain the behavior of the studied case for its shell permeability $(\mathrm{K}=1.25$ *10-5 m/s) during the rapid drawdown, Figure (7) illustrates the slip shear resistance and shear mobilized under the slices of the critical slip surfaces for initial conditions and during various drawdown times. At the initial condition, shear resistance is much greater than the shear mobilized; the factor of safety was 2.335 . From the beginning of the drawdown process until the end, the difference between shear mobilized and shear 
resistance becomes smaller, but never the value of shear mobilized larger than shear resistance, this indicated that the structure is safe during sudden drawdown.

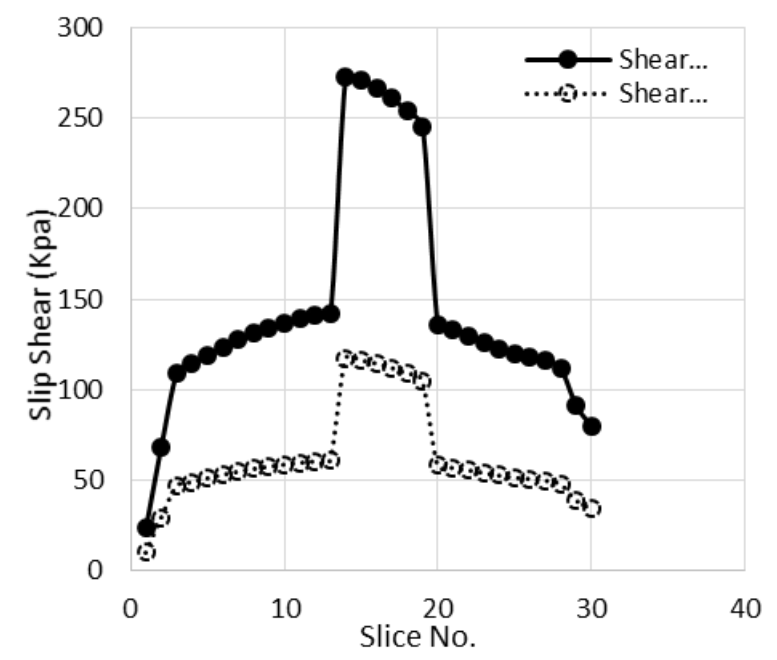

(a)

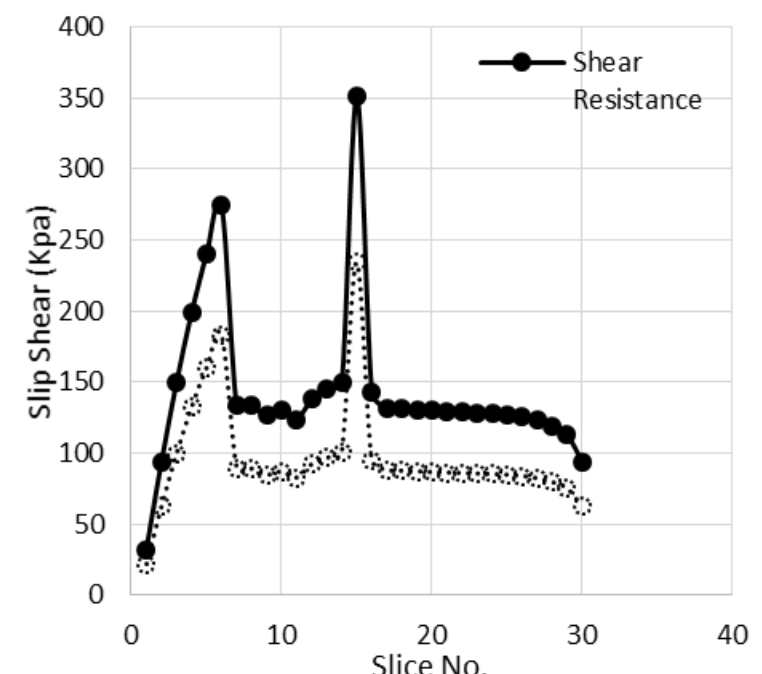

(c)

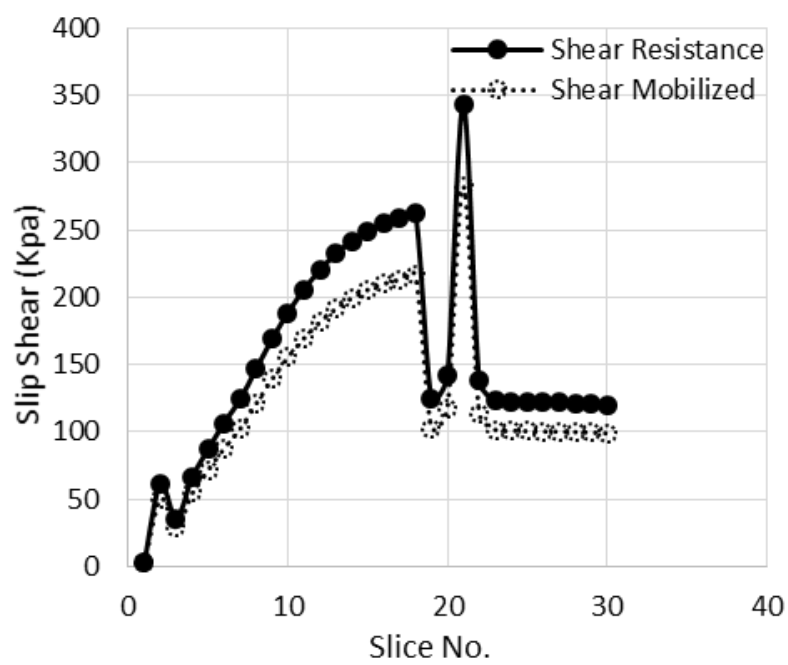

(e)

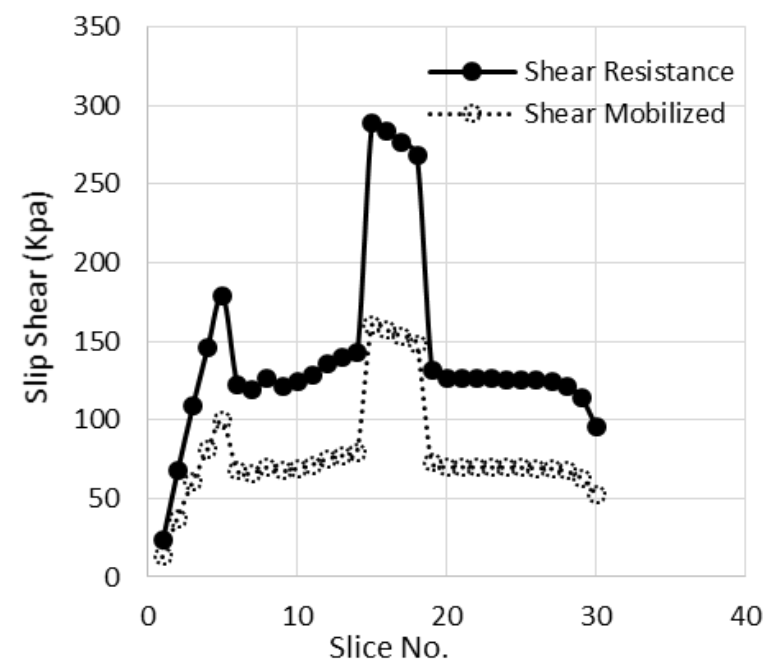

(b)

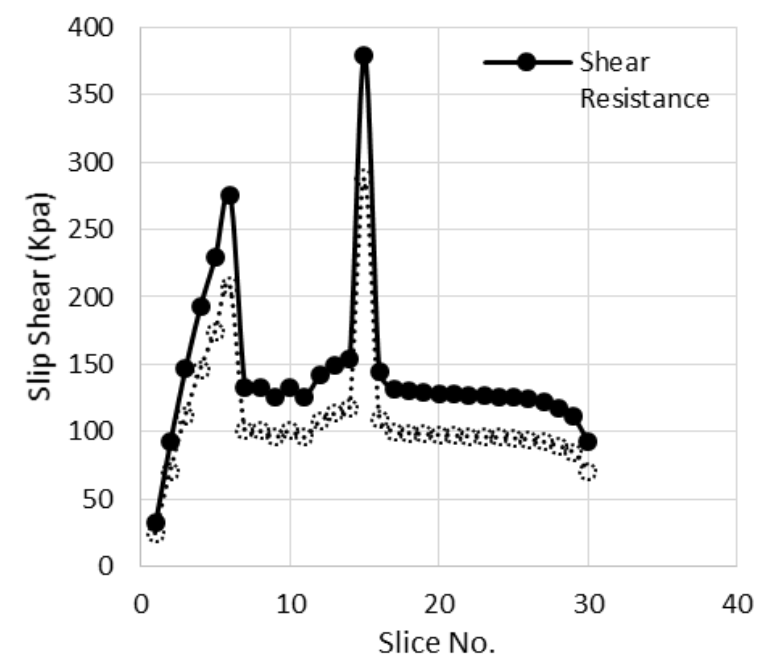

(d)

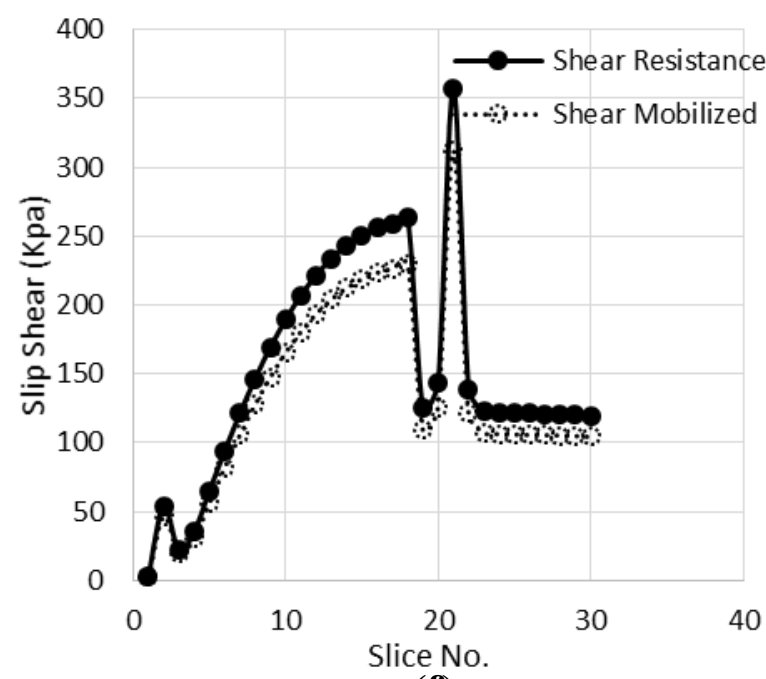

(f)

Fig. 7: Slip shear resistance and slip shear mobilized under slices of critical slip surface at (a) initial condition, (b) 5.4 days, (c) 10.4 days, (d) 15.4 days, (e) 19.8 days, and (f) 25.5 days. 
An investigation of transient seepage circumstances is used to determine the effect of the permeability of the shell material on the pore water pressure at various places. Figure (8) shows five sites in the dam's upstream shell and core. Figure (9) depicts the fluctuation in pore water pressure over time for various shell permeability in the reservoir under drawdown conditions at locations 1, 2, 3, 4, and 5. (9). According to the findings, the permeability of shell material has a considerable impact on pore water pressure, with increased permeability resulting in a large reduction in pore water pressure over time. Furthermore, as compared to soil with high permeability, pore water pressure in low permeability soil remains high.

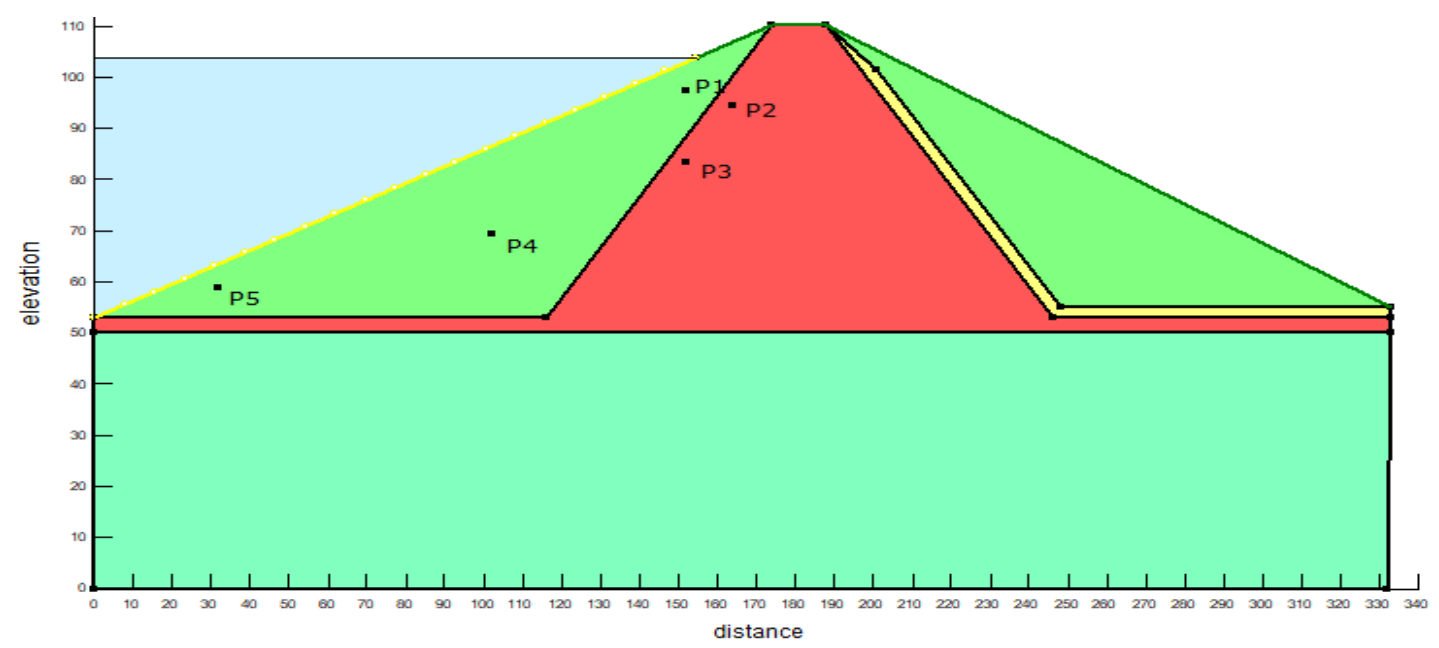

Fig. 8: Showing points on the dam body

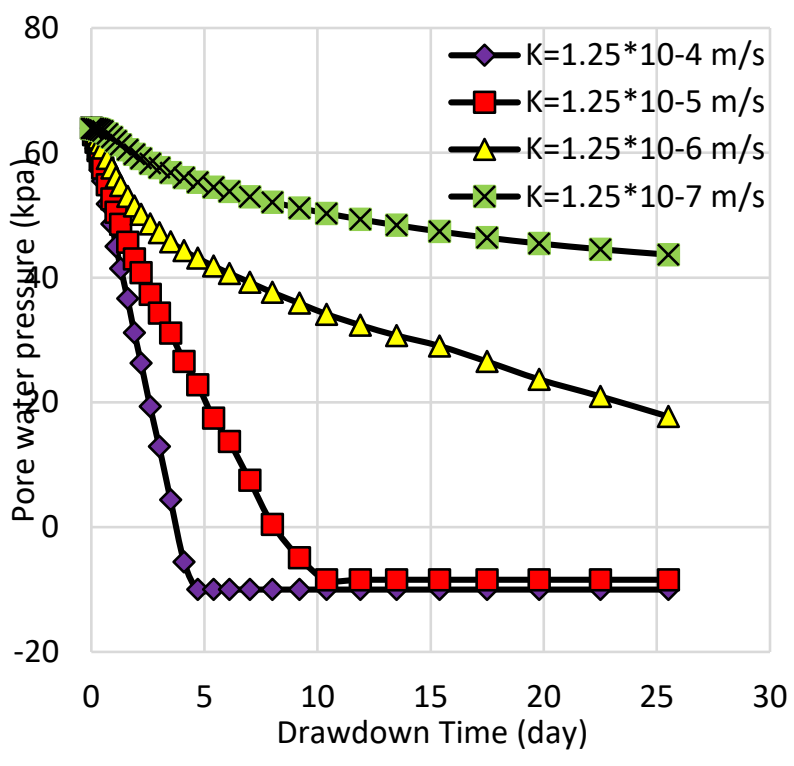

(a)

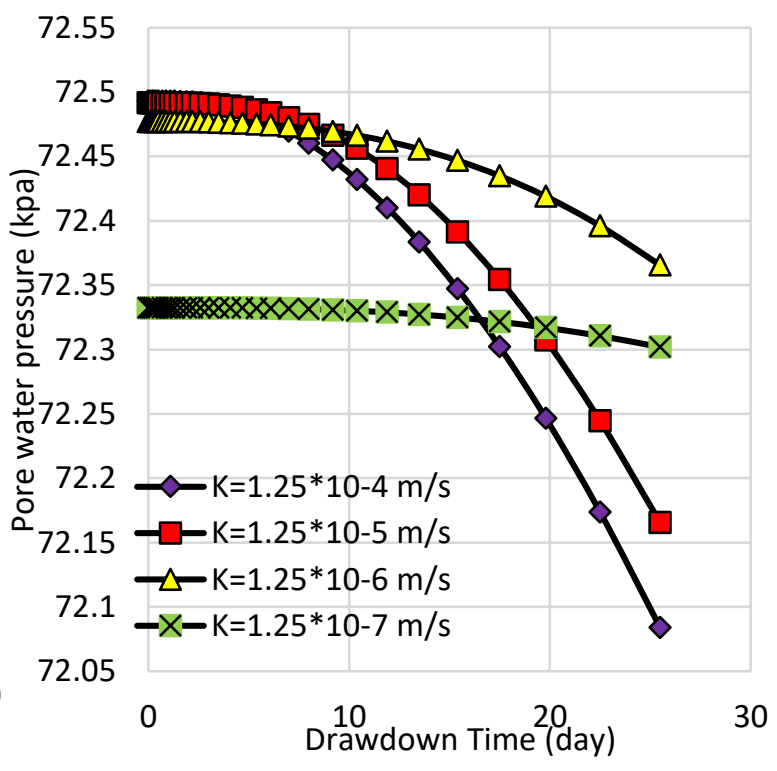

(b) 


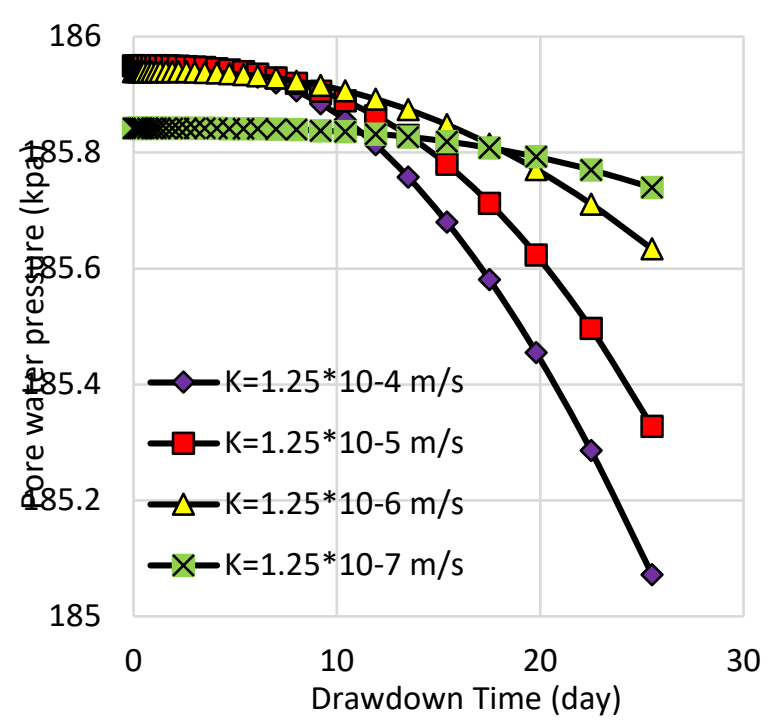

(c)

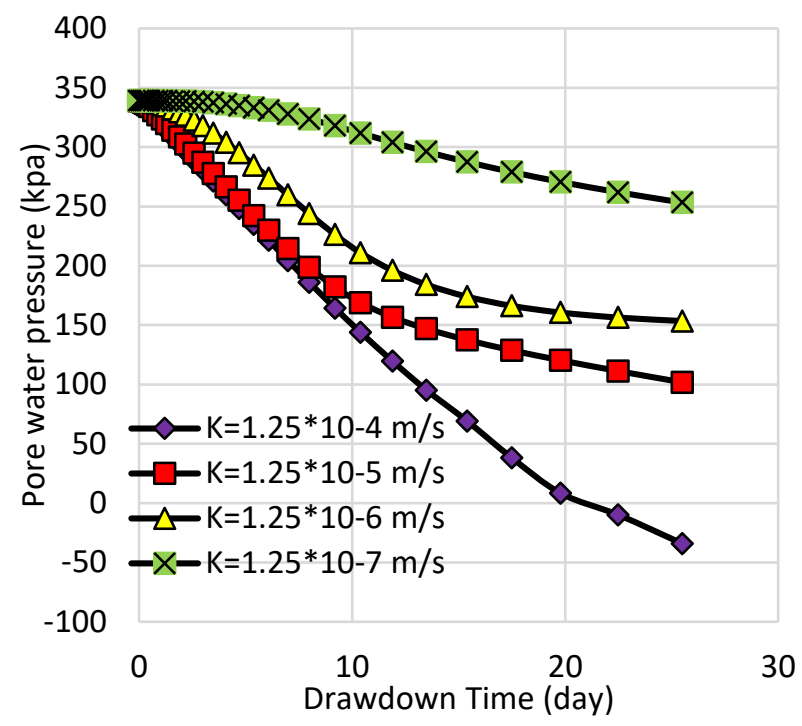

(d)

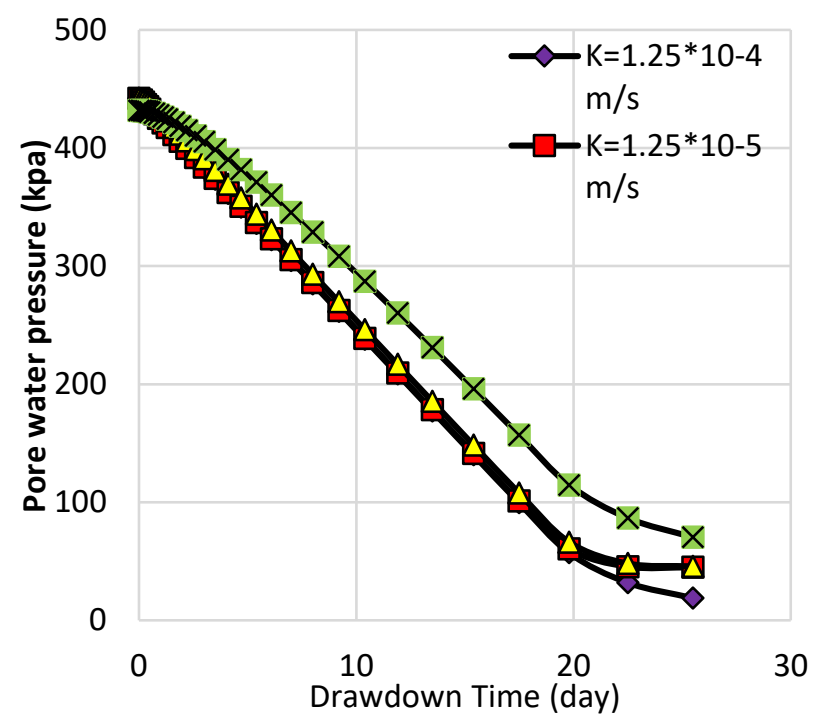

(e)

Fig. 9: Pore water pressure variation with time during the drawdown in the reservoir at (a) point 1, (b) point 2, (c) point 3, (d) point 4, (e), and point 5.

Regarding the variation of pore water pressure in points 2 and 3 located in the core component due to the low permeability of core material, dissipating the water takes more time, therefore, pore water pressure in the soil remains high. As a result, the shear resistance was reduced and large shear stress developed. In contrast, pore water pressure placed at points 1, 4, and 5, in the shell upstream side falls linearly with time. Based on the figures, the permeability value of $\left(\mathrm{K}=1.25 * 10^{-7} \mathrm{~m} / \mathrm{s}\right)$ results in a slight reduction in pore water pressure, however for $\left(\mathrm{K}=1.25 * 10^{-4} \mathrm{~m} / \mathrm{s}\right)$, there is a remarkable drop of it. Thus, for drawdown conditions, high permeable soils can be suggested for the shell of the dam. 


\section{CONCLUSION}

High soil permeability raises the factor of safety for the upstream slope because, in the case of drawdown, higher permeability allows for the dissipation of water, resulting in increased shear resistance of the material and, as a consequence, increased strength of the dam upstream slope material. The findings of this study show that the most problematic condition for the upstream side with poor permeability material is a rapid drop in water in the reservoir since the water inside the soil cannot drain rapidly, causing the dam upstream face to become unstable. In this investigation, it was discovered that the Morgenstern-Price approach has a higher value for the safety factor, whereas the Janbu method is the most cautious. Furthermore, pore water pressure remained high when soil permeability was poor, depending on the results. Excess pore water pressure can reduce soil shear strength, and it is a reason for the failure of the dam.

\section{REFERENCES}

Abbas, J. M., Aljanabi, Q. A., and Mutiny, Z. A., 2017. Slope Stability Analysis of an Earth Dam. Diyala Journal of Engineering and Science, March, 10(1), pp. 106117.

Alfatlawi, T. J. M., Al-temimi, Y. K. And Alomari, Z. M., 2020. Evaluation of the upstream slope stability of earth dams based on drawdown conditions - Khassa Chai Dam: a case study. Babylon, 3rd International Conference on Engineering Sciences IOP Conf. Ser.: Mater. Sci. Eng. 671012072.

Beiranvand, B., Mohammadzade, A., and Komasi, M.,, 2019. Effect Of Different Parameters Of Heterogeneous Dams On Safety Factor Using The Neural Network. Case Study: Marvak Dam. Nexo Revista Ceintifica, 32(2), pp. 126-138.

Berilgen, M. M., 2007. Investigation of stability of slopes under drawdown conditions. Computers and Geotechnics, 34(2), pp. 81-91.

Bishop, A. W. and Morgenstern, N., 1960. Stability coefficients for earth slopes. Geotechniques, 4(10), pp. 164-169.

Bishop, A. W., 1955. The use of slip circle in the stability analysis of slopes. Geotechniques, 1(5), pp. 7-17.

Duncan, JM., Wrigth, SG., and Wong, KS., 1990. Slope stability during rapid drawdown. S.1., s.n., pp. 253-272.

Center of Engineering Designs and Studies, (2007), Khassa Chai dam Planning Report.

Fellenius, W., 1936. Calculation of stability of earth dams. S.1., s.n., pp. 445-463.

Janbu, N., 1954. Applications of composite slip surfaces for stability analyses. Stockholm, s.n., pp. 39-43.

Janbu, N., 1968. Slope Stability computations, Trondheim: s.n. 
Khassaf, S. I. And Madhloom, A. M., 2019. Stability Analysis of Zoned Earth Dam under Effect of the Most Dangerous Conditions (Case Study: Khassa Chai Dam). International Journal of Scientific and Engineering Research, 10(12).

Malekpour, A., Farsadizadeh, D., Hosseinzadeh Dalir, A. and Sadrekarimi, J., 2012. Effect of horizontal drain size on the stability of an embankment dam in steady and transient seepage conditions. Turkish Journal of Engineering, Environmental, and Science, Issue 36, pp. 139-152.

Mishal, U. R. and Khayyum, T. Sh., 2018. Stability Analysis of an Earth Dam Using GEO-SLOPE Model under Different Soil Conditions. Engineering and Technology Journal, 36(5), pp. 523-532.

Moharrami, A., Hassanzadeh, Y., Salmasi, F. And Moradi, G., 2013. Performance of the horizontal drains in upstream shell of earth dams on the upstream slope stability during rapid drawdown conditions. Arabian Journal of Geosciences, May.

Morgenstrern, N.R. and Price, V.E., 1965. The analysis of the stability of general slip surfaces. Geotechnique, 1(15), pp. 79-93.

Noori, K. M. G., Ibrahim, H. H. And Hassan, A. M., 2018. Influence of Upstream Blanket on Earth Dam Seepage. Eurasian Journal of Science and Engineering, 4(1), p. 123.

Rulon, J.J. and Freeze, R.A., 1985. Multiple Seepage faces on layered slopes and their implications for slope stability analysis. Canadian Geotechnical Journal, Volume 22.

Salim, S. G., 2013. The effect of structural geometry on stability and deformation of zoned earth-fill dam, Nottingham: s.n.

SEEP/W, 2012. Geo-Slope International Ltd., Seepage Modeling with SEEP/W 2012: An Engineering Methodology. In: 6th, ed. Alberta:: Geo-Slope International Ltd., Seepage Modeling with SEEP/W 2012: An Engineering Methodology.

SLOPE/W, 2012. Geo-Slope International Ltd., Stability Modelling with SLOPE/W 2012: An Engineering Methodology. In: 6th, ed. Alberta:: Geo-Slope International Ltd.

Zedan, A. J., Faris, M. R., and Abdulsattar, A. A., 2017. Seepage Analysis through an Earth Dam (Khassa-Chai Dam) as a Case Study. Engineering and Technology Journal, Vol. 35(Part A. No. 2). 